\title{
EVALUATING GLOBAL BIODIVERSITY HOTSPOTS - VERY RICH AND EVEN MORE ENDANGERED
}

\author{
ALEŠ HRDINA $^{1}$, DUŠAN ROMPORTL ${ }^{1}$ \\ ${ }^{1}$ Department of Physical Geography and Geoecology, Faculty of Science, Charles \\ University, Albertov 6, 12843 Prague 2, Czech Republic, \\ e-mails: ales.hrdina@natur.cuni.cz,dusan@natur.cuni.cz.
}

Received: $31^{\text {th }}$ March 2017, Accepted: $9^{\text {th }}$ June 2017

\begin{abstract}
Species on the Earth are under increasing human pressure, according to some authors, the current rate of extinction occurred only a few times in the past, for the last time in the Cretaceous Period in the Mesozoic Era. The main goal of current nature conservation is to maintain the highest native biological diversity and to preserve and enhance life-supporting ecosystem processes, functions and services with the best possible use of financial resources. The areas where can be found the highest concentrations of endemic species and that also face the highest loss of natural habitats are called biodiversity hotspots. Globally, now there are 36 hotspots, covering $2.4 \%$ of the Earth's land area and harbouring about $50 \%$ of endemic plant species and $42 \%$ of endemic terrestrial vertebrate species in the world. The areas can be compared in terms of species richness, endemism, natural habitat loss or territorial protection and nature conservation can be carried out in the most efficient way. The most important hotspots are Madagascar and the Indian Ocean Islands and Sundaland.
\end{abstract}

Keywords: biodiversity, hotspots, endemism, threats, conservation

\section{INTRODUCTION}

British ecologist Norman Myers first introduced the concept of terrestrial biodiversity hotspots, very important areas for biological conservation, in 1988 he identified ten hotspots in the tropical forest biome (Myers, 1988). At that time, there were no quantitative criteria to define areas of biodiversity hotspots (Mittermeier et al., 2004). Two years later, in 1990, he added eight hotspots, including four areas of Mediterranean type ecosystems (Myers, 1990). Conservation International adopted Myers' concept of hotspots in 1989 (Mittermeier et al., 1998) and in 1999 were introduced quantitative biodiversity hotspots identification criteria (Conservation International, 2014). Generally, such areas must meet two criteria: a hotspot must harbour 1,500 or more vascular plant species being endemics there and has to have lost at least $70 \%$ of its original primary habitat. The number of hotspots increased to 25 , covering $1.4 \%$ of the Earth's land area and maintaining $44 \%$ of the world's plant species and $35 \%$ of terrestrial vertebrate species, and then again to 34. This number of hotspots lasted until 2011, comprising $2.3 \%$ of the land surface and supporting more than $50 \%$ of endemic plant species and $42 \%$ of the world's endemic terrestrial vertebrate species (CEPF, 2014). Now there are 36 hotspots, covering $2.4 \%$ of the land surface. Forests of East Australia were identified in 
2011 and North American Coastal Plain in 2016 (Williams et al., 2011; Noss et al., 2015; CEPF, 2016).

The boundaries of biodiversity hotspots were determined by common biological features. Each of the areas is a unique biogeographic unit. This is evident in the case of islands or archipelagos and the same is true for continental ecological islands in clearly defined units. Typical examples are the Philippines, Japan, the East Melanesian Islands, New Caledonia, Polynesia-Micronesia, New Zealand, the Caribbean Islands, Madagascar and the Indian Ocean Islands or Southwest Australia, the Caucasus and the Cape Floristic Province, respectively. In some other areas are the boundaries defined by the lines of recognized divisions such as Wallace's line between Wallacea and Sundaland, or according to the expert judgement (Myers et al., 2000).

Along with the development of the terrestrial hotspots biodiversity concept were also identified the least endangered areas with high biodiversity. Wilderness areas are quantitatively defined as areas still harbouring more than $70 \%$ of the original habitat area and with population density lower than 5 people per $\mathrm{km}^{2}$. These criteria are met by $44 \%$ of the land surface, but high biodiversity wilderness areas, which must also meet the criterion of more than 1,500 endemic plant species, cover only $6.1 \%$ of the total area in 5 regions: Amazonia, the North American Deserts, the Congo Forests of Central Africa, the Miombo-Mopane Woodlands and Grasslands of Southern Africa and New Guinea. In the five areas is found $17 \%$ of endemic plant species and $8 \%$ of the world's endemic terrestrial vertebrate species (Mittermeier et al., 2004). Besides terrestrial biodiversity hotspots there were also identified ten marine biodiversity hotspots: South Japan, the Gulf of Guinea, the North Indian Ocean, Eastern South Africa, the Cape Verde Islands, the West Caribbean, the Philippines, the Red Sea and the Gulf of Aden, the South Mascarene Islands, the Sunda Islands (Roberts et al., 2002). There are many approaches, based on the ecological criteria of vulnerability and irreplaceability, and their combinations, how to identify global conservation priorities. Conservation International uses a two-pronged strategy for prioritizing global conservation. At the same time is focusing on the threatened and irreplaceable terrestrial biodiversity hotspots and on the high biodiversity wilderness areas, which are also irreplaceable but still largely intact and providing significant conservation opportunities (Conservation International, 2014).

The hotspot concept has also many critics. Peter Kareiva and Michelle Marvier (2003) argued that the hotspot idea attracted too many financial resources and other areas playing a significant ecological role are downplayed. By investing exclusively in hotspots we risk to lose important areas that contribute to many ecosystem services. Similarly Jepson and Canney (2001) think that biodiversity hotspots concept provides only a partial response. From another point of view, Cañadas et al. (2014) claim that hotspots are to large for effective conservation and they detect smaller hotspots within larger hotspots. Stork and Habel (2014) criticize identifying biodiversity hotspots without considering invertebrates. Marine biodiversity hotspots have also been the subject of controversy (Marchese, 2015).

\section{BIODIVERSITY WITHIN HOTSPOTS}

Natural environment and geographical conditions of biodiversity hotspots have been attracting over a long period a large number of fauna and flora species. There are, based on the CEPF (2014) data, more than 150,000 endemic plant species, half of all species of the world. The highest number of species, about 30,000 vascular plant species, grows in the Tropical Andes. The next hotspots ranked include Sundaland, the Mediterranean Basin and 
Atlantic Forest with more than 20,000 species. Special attention should be paid to Madagascar and the Indian Ocean Islands, where 9 of 10 species are endemic.

The highest mammal species richness - 570 species - can be found in the Tropical Andes, similarly in Indo-Burma, Mesoamerica and the Eastern Afromontane hotspot. The largest proportion of endemic species can be found within all the island hotspots; in the foreground is as usual Madagascar with $92.9 \%$. The top positions in bird diversity belong to the same four hotspots, complemented by species-rich hotspots Himalaya or South American Atlantic Forest or Tumbes-Chocó-Magdalena. Especially three regions are important with respect to amphibian diversity: American hotspots the Tropical Andes, Mesoamerica and Atlantic Forest; Southeast Asian hotspots Indo-Burma and Sundaland; East African hotspots Madagascar and the Indian Ocean Islands and the Eastern Afromontane. On the other hand New Caledonia has no amphibian species. Most reptile species are located in the same three regions, the most important region being Central America and the Caribbean. The Mekong, Chao Phraya, Salween and Irrawaddy river basins are extremely rich in freshwater fish species, Indo-Burma is inhabited by 1,262 and Sundaland 950 species. Species-rich are also rivers and lakes of the East African Rift, the Eastern Afromontane hotspot harbouring 893 species. The Cerrado gets ranking number four with 800 freshwater fish species.

\section{THREATS FOR BIODIVERSITY}

Threats in biodiversity hotspots are the same as those that threaten biodiversity worldwide, having been only more intensive there. Habitat fragmentation, degradation, destruction and loss are a pervasive threat affecting hotspots (Brooks et al., 2002). Anthropogenic acceleration of climate change magnifies the effects of habitat fragmentation, degradation and loss (Thomas et al., 2004). The average proportion of land area per hotspot with novel climate was modelled to be about $16 \%$. The distribution of novel and disappearing climate are principally concentrated at low latitudes (Bellard et al., 2014). Predatory invasive alien species have already had a devastating impact on the island hotspots, where species evolved in the absence of predators. Introduction of invasive alien plant species, particularly those of Mediterranean-type vegetation, is also having massive ecosystem effects. Direct wildlife exploitation for food, pet trade, or medicine is a serious threat to all hotspots (CEPF, 2014). In biodiversity hotspots live about 2 billion people. However, the relationship between people and biodiversity is not simply one where presence of more people results in greater impacts on biodiversity. For human-biodiversity interactions is more important human activity than human density (Mittermeier et al., 2004). Biodiversity hotspots are also notable centres of violent conflict (Dudley et al., 2002).

\section{EVALUATION OF HOTSPOTS' IMPORTANCE}

The analysis by Myers et al. (2000) was driven by two criteria: species endemism and degree of threat, and considered five key factors: numbers of endemics and endemic/species ratios for plants and vertebrates, and habitat loss. Hotspots, which appeared most often in the top ten listings for each factor, were the leaders. Scientific knowledge has deepened, the number of hotspots has increased. These are the main reasons for the new analysis. In this analysis was used modified Myers' method for mutual comparison of the quality of biodiversity hotspots, which considered thirteen factors (instead of five): numbers of endemics and endemic/species ratios for plants, mammals, birds, amphibians, reptiles and freshwater fishes, and habitat loss. These factors do not carry equal weight, so they cannot be 
combined into a single quantitative ranking. For the purposes of qualitative comparison were compiled the rankings of each factor. Due to the higher number of hotspots, 36 instead of 25 were considered top twelve listings for each factor. As a proxy indicator was used the sum of all factors rankings. For assessing the distribution of national parks in hotspots, was used a database (based on the WDPA dataset), analysed in GIS.

Biodiversity hotspots, appearing for all thirteen factors in the top twelve listings, are the most important on the world's terrestrial surface. These are Madagascar and the Indian Ocean Islands and Sundaland followed by the Philippines appearing twelve times and the Caribbean Islands appearing eleven times. All the areas are island hotspots, most of them being small areas, making them even more important. Next ranking numbers get to the Atlantic Forest, scoring also eleven times, Indo-Burma nine times, the Tropical Andes eight times and Mesoamerica and the Eastern Afromontane seven times. The six richest hotspots in terms of biodiversity are those with the lowest proportion of the remaining natural vegetation, reaching in Madagascar and the Indian Ocean Islands and the Caribbean Islands hotspots $10 \%$, others displaying even smaller proportion.

Some other hotspots are hot conservation candidates because they greatly excel in one of the factors. The Mediterranean Basin has exceptional totals of endemic plants: 13,000, while the proportion of remaining natural vegetation is the smallest among all the hotspots. The Cape Floristic Region displays the second highest endemic species/area ratio for plants, just after the first New Caledonia. Although some of the biodiversity hotspots do not appear in the top twelve listings in any factor, they still must meet the criteria to qualify themselves as a hotspot and in comparison with the rest of the world have extraordinarily high species richness and endemism rate. The nine hotspots are Forests of East Australia, Himalaya, the California Floristic Province, the Chilean Winter Rainfall Valdivian Forests, Southwest Australia, Irano-Anatolian, Maputaland-Pondoland-Albany, the Caucasus and the Mountains of Central Asia.

Formerly 36 biodiversity hotspots covered an area of almost 24.9 million square kilometres, i.e. $16.7 \%$ of the Earth's land surface (CEPF, 2014; CEPF, 2016). The area of the original primary habitat has been gradually decreasing there over the years, nowadays reaching 3.6 million square kilometres, i.e. $2.4 \%$ of the Earth's land surface. The area of the original biodiversity hotspots' habitat was reduced by $85.5 \%$, only $14.5 \%$ still remains. The average area of remaining vegetation is now only $100,224 \mathrm{~km}^{2}$, which is almost seven times less than the original area. Generally, hotspots located outside the highly productive tropics in temperate or subtropical zone, have a larger proportion of the remaining natural vegetation. The northern hemisphere situated hotspots: the California Floristic Province, the Caucasus, the Mountains of Central Asia and Japan; and in the southern hemisphere: the Chilean Winter Rainfall-Valdivian Forests, the Succulent Karoo, the Cape Floristic Region, Maputaland-Pondoland-Albany, Southwest Australia and New Zealand, still having had $20 \%$ or more of the original habitat area remaining. The only exception is the Mediterranean Basin, showing the lowest proportion due to the long-term and continuing human exposure. They are also located in developed countries (the United States, Japan, Australia, New Zealand), or in Chile and South Africa, known for their traditional and quite developed nature conservation.

The distribution of hotspots across biomes is very unequal. Of the total 36 biodiversity hotspots, 22 are located in the tropics, from very humid areas to sparsely wooded areas of savannas and grasslands. Seven hotspots are situated in the temperate forests biome: the Caucasus, the Irano-Anatolian hotspot, the Mountains of Central Asia, the Mountains of Southwest China, Japan, New Zealand and North American Coastal Plain; six can be characterised by the Mediterranean vegetation: the California Floristic Province, the Chilean 
Winter Rainfall-Valdivian Forests, the Cape Floristic Region, Southwest Australia, the Mediterranean Basin and the Horn of Africa; and one - the Succulent Karoo - is desert.

\section{NATURE CONSERVATION}

Approximately 2.7 million square kilometres, i.e. $10.9 \%$ of the total area of hotspots has already been at least officially protected. The proportion of protected areas varies between individual hotspots in a wide range from $3.2 \%$ to $37 \%$. Two of the five most important hotspots, Madagascar and the Indian Ocean Islands, and Atlantic Forest, have the lowest proportion of area under some types of territorial protection, only $3.2 \%$ and $4.1 \%$, respectively. Protected areas in IUCN categories I-IV provide higher levels of protection, because they control to various extent resource use and human presence. The average coverage of protected areas in categories I-IV is $5.0 \%$ within the hotspots' original area, in total reaching $1,248,258 \mathrm{~km}^{2}$. Generally, hotspots situated outside the tropics have above-average proportion of protected areas in IUCN categories I-IV, from New Zealand with $22.1 \%$ to Japan with $5.9 \%$. The exception is again the Mediterranean Basin and then also a specific desert hotspot, namely the Succulent Karoo. National parks (as defined in national legislations) cover an area of $1,043,308.52 \mathrm{~km}^{2}$, the proportion of the total hotspots' area is $4.2 \%$. In all 36 biodiversity hotspots has been established 1,858 national parks of the total number of 3,375 so far. Thus, in the hotspots is situated more than every second of the world's national parks, but only $24 \%$ of their total area is there. It is caused by the low average size of national parks in the highly fragmented landscape of hotspots.

Biodiversity hotspots are irreplaceable areas at high risk, with significant species richness, diversity and endemism. They deserve the most attention in the process of conservation, together with high biodiversity wilderness areas, also irreplaceable but still largely intact. In 2000 was established the Critical Ecosystem Partnership Fund focusing exclusively on the funding of conservation activities in the areas of biodiversity hotspots, particularly from U.S. private foundations (Dalton, 2000). The concept has attracted over $\$ 1$ billion in conservation investments (Mittermeier et al., 2011). Almost thirty of the 50 countries with the most underfunded biodiversity conservation programmes and projects host the global biodiversity hotspots: therefore, much more funding is required there (Waldron et al., 2013).

\section{CONCLUSION}

Every day biodiversity is being lost at up to 1,000 times the natural rate. The extinction of species, habitat destruction, land conversion, climate change, pollution or the spread of invasive species are only some of the threats responsible for today's crisis (IUCN, 2010). For the first time in human history, the rate of species extinction may exceed that of species discovery (Wheeler et al., 2012). Traditionally among the main responses to the current biodiversity crisis, there also is the establishment and effective management of protected areas to ensure the persistence of biodiversity not only in the hotspots (Bruner et al., 2001). Surprisingly high number of currently existing protected areas are no more than "paper parks", it means they have official designation, but lack management plans, funding, capacity or enforcement and in some cases, even borders. Mismanagement also includes biodiversity conservation (CEPF, 2014). The main objectives of the current global conservation should be, inter alia, ensuring long-term stability in the already declared protected areas, reducing fragmentation and then also establishing new protected areas in places with intact habitat with the highest conservation priority (Mittermeier et al., 2004). Climate change is likely to 
have a large impact on biodiversity. Establishing protected areas that remain resistant and resilient to climate change as well as new ones in novel ecosystems is a further challenge (Araújo et al., 2004; Hannah et al., 2007; Bellard et al., 2014). Species movement including dispersal may be very difficult or impossible in heavily fragmented habitat (Thomas, 2011). Therefore, it is necessary to protect also the areas that will host target species in the near future and to establish, manage and protect the corridors, both linear ones and stepping stones (Mittermeier et al., 2004). The long-term goal is to attempt to restore degraded habitats to provide increased connectivity and to decrease fragmentation (CEPF, 2014).

Biodiversity hotspots and high biodiversity wilderness areas are inhabited by two-thirds of endemic plant species and half of the world's endemic species of terrestrial vertebrates in only $8.5 \%$ of the Earth's land surface. Hotspots provide us with the real measure of the conservation challenge. Unless we succeed in conserving this small fraction of the planet's land area, we will lose more than half of our natural heritage (CEPF, 2014).

To conclude, the analysis evaluates 36 instead of 25 hotspots that existed in 2000 . The current available species data are more complete and accurate, so they allow consideration of 13 factors instead of 5 and more precise results of biodiversity hotspots' importance. Hotspots with the highest conservation priority are Madagascar and the Indian Ocean Islands, Sundaland, the Philippines and the Caribbean Islands, all island hotspots, with the lowest proportion of the remaining natural vegetation, located in the tropics. Effective conservation in the areas of biodiversity hotspots must be among the tasks of high priority at present and in the near future.

\section{REFERENCES}

Araújo, M.B., Cabeza, M., Thuiller, W., Hannah, L., Williams, P.H. (2004). Would climate change drive species out of reserves? An assessment of existing reserve-selection methods. Global Change Biology 10: 1618-1626.

Bellard, C., Leclerc, C., Leroy, B., Bakkenes, M., Veloz, S., Thuiller, W., Courchamp, F. (2014). Vulnerability of biodiversity hotspots to global change. Global Ecology and Biogeography 23:1376-1386.

Brooks, T.M., Mittermeier, R.A., Mittermeier, C.G., Da Fonseca, G.A.B., Rylands, A.B., Konstant, W.R., Flick, P., Pilgrim, J., Oldfield, S., Magin, G., Hilton-Taylor, C., (2002). Habitat Loss and Extinction in the Hotspots of Biodiversity. Conservation Biology 16:909-923.

Bruner, A.G., Gullison, R.E., Rice, R.E., Da Fonseca, G.A.B. (2001). Effectiveness of Parks in Protecting Tropical Biodiversity. Science 291:125-128.

Cañadas, E.M., Fenu, G., Peñas, J., Lorite, J., Mattana, E., Bacchetta, G. (2014). Hotspots within hotspots: Endemic plant richness, environmental drivers, and implications for conservation. Biological Conservation 170:282-291.

CEPF (Critical Ecosystem Partnership Fund) - The Biodiversity hotspots (2014, November). Retrieved on November 7, 2014 from http://www.cepf.net/resources/hotspots/Pages/ default.aspx.

CEPF (Critical Ecosystem Partnership Fund) - Announcing the World's 36th Biodiversity Hotspot: The North American Coastal Plain (2016, November). Retrieved on February 14, 2016 from http://www.cepf.net/news/top_stories/Pages/Announcing-the-Worlds-36thBiodiversity-Hotspot.aspx. 
Conservation International - Hotspots (2014, January). Retrieved on January 18, 2017 from http://www.conservation.org/where/priority_areas/hotspots/

Dalton. R. (2000). Biodiversity cash aimed at hotspots. Nature 406:818.

Dudley, J.P., Ginsberg, J.R., Plumptre, A.J., Hart, J.A., Campos, L.C. (2002). Effects of War and Civil Strife on Wildlife and Wildlife Habitats. Conservation Biology 16:319-329.

Hannah, L., Midgley, G., Andelman, S., Araújo, M., Hughes, G., Martinez-Meyer, E., Pearson, R., Williams, P. (2007). Protected area needs in a changing climate. Frontiers in Ecology and the Environment 5: 131-138.

IUCN - The IUCN Red List of Threatened Species (2010, September). Why is biodiversity in crisis? Retrieved on October 26, 2016 from http://www.iucnredlist.org/news/ biodiversity-crisis

Jepson, P., Canney, S. (2001). Biodiversity hotspots: hot for what? Global Ecology and Biogeography 10:225-227.

Kareiva, P., Marvier, M. (2003). Conserving Biodiversity Coldspots. American Scientist 91:344-351.

Marchese, C. (2015). Biodiversity hotspots: A shortcut for a more complicated concept. Global Ecology and Conservation 3:297-309.

Mittermeier, C.G., Turner, W.R., Larsen, F.W., Brooks, T.M., Gascon, C. (2011). Global biodiversity conservation: the critical role of hotspots. In: Zachos FE, Habel JC (eds) Biodiversity Hotspots: Distribution and Protection of Priority Conservation Areas (pp 3-22). Springer-Verlag, Berlin.

Mittermeier, R.A., Myers, N., Thomsen, J.B., Da Fonseca, G.A.B., Olivieri, S. (1998). Biodiversity Hotspots and Major Tropical Wilderness Areas: Approaches to Setting Conservation Priorities. Conservation Biology 12:516-520.

Mittermeier, R.A., Hoffmann, M., Pilgrim, J., Brooks, T., Lamoreux, J., Mittermeier, C.G., Gil, P.R., Da Fonseca, G.A.B., (2004). Hotspots revisited: Earth's biologically richest and most endangered terrestrial ecoregions. CEMEX, Mexico City

Myers, N., (1988). Threatened biotas: 'hotspots' in tropical forests. Environmentalist 8:187- 208.

Myers, N., (1990). The biodiversity challenge: expanded hotspots analysis. Environmentalist 10:243-256.

Myers, N., Mittermeier, R.A., Mittermeier, C.G., Da Fonseca, G.A.B., Kent, J. (2000). Biodiversity hotspots for conservation priorities. Nature 403:853-858.

Noss, R.F., Platt, W.J., Sorrie, B.A., Weakley, A.S., Means, D.B., Costanza, J., Peet, R.K. (2015). How global biodiversity hotspots may go unrecognized: lessons from the North American Coastal Plain. Diversity and Distributions 21:236-244.

Roberts, C.M., McClean, C.J., Veron, J.E.N., Hawkins, J.P., Allen, G.R., McAllister, D.E., Mittermeier, C.G., Schueler, F.W., Spalding, M., Wells, F., Vynne, C., Werner, T.B. (2002). Marine Biodiversity Hotspots and Conservation Priorities for Tropical Reefs. Science 295:1280-1284.

Stork, N.E., Habel, J.C. (2013). Can biodiversity hotspots protect more than tropical forest plants and vertebrates? Journal of Biogeography 41:421-428.

Thomas, C.D., Cameron, A., Green, R.E., Bakkenes, M., Beaumont, L.J., Collingham, Y.C., Erasmus, B.F.M., De Siqueira, M.F., Hughes, L., Hannah, L., Grainger, A., Huntley, B., Van Jaarsveld, A.S., Midgley, G.F., Miles, L., Ortega-Huerta, M.A., Peterson, A.T., 
Phillips, O.L., Williams, S.E. (2004). Extinction risk from climate change. Nature 427:145-148.

Thomas, C.D. (2011). Translocation of species, climate change, and the end of trying to recreate past ecological communities. Trends in Ecology and Evolution 26:216-221.

Waldron, A., Mooers, A.O., Miller, D.C., Nibbelink, N., Redding, D., Kuhn, T.S., Roberts, J.T., Gittleman, J.L. (2013). Targeting global conservation funding to limit immediate biodiversity declines. PNAS USA 110: 12144-12148.

Wheeler, Q.D., Knapp, S., Stevenson, D.W., Stevenson, J., Blum, S.D., Boom, B.M., Borisy, G.G., Buizer, J.L., De Carvalho, M.R., Cibrian, A., Donoghue, M.J., Doyle, V., Gerson, E.M., Graham, CH., Graves, P., Graves, S.J., Guralnick, R.P., Hamilton, A.L., Hanken, J., Law, W., Lipscomb, D.L., Lovejoy, T.E., Miller, H., Miller, J.S., Naeem, S., Novacek, M.J., Page, L.M., Platnick, N.I., Porter-Morgan, H., Raven, P.H., Solis, M.A., Valdecasas, A.G., Van Der Leeuw, S., Vasco, A., Vermeulen, N., Vogel, J., Walls, R.L., Wilson, E.O., Woolley, J.B. (2012). Mapping the biosphere: exploring species to understand the origin, organization and sustainability of biodiversity. Systematics and Biodiversity 10:1, 1-20.

Williams, K.J., Ford, A., Rosauer, D.F., De Silva, N., Mittermeier, R.A., Bruce, C., Larsen, F.W., Margules, C. (2011). Forests of East Australia: The 35th Biodiversity Hotspot. In: Zachos FE, Habel JC (eds) Biodiversity Hotspots: Distribution and Protection of Priority Conservation Areas (pp 295-310). Springer-Verlag, Berlin. 